\title{
Using Multimedia to Create a Scientific English Teaching Model of Human- Computer Interaction
}

\author{
Zhang Weihong \\ English Department \\ Hebei Tourism Vocational College \\ Chengde City, Hebei Province, P.R. China \\ mayzhwh@yahoo.com.cn
}

\author{
Zhang Chunying \\ Foreign Languages and Cultures \\ Beijing Wuzi University \\ Beijing, P.R. China \\ Zhangchunying1979@sina.com
}

\begin{abstract}
Multimedia Computer Assisted Instruction (CAI) has brought many changes to teacher-student interaction in the English class. CAI not only brightens up the classroom environment, but also stimulates students' interest in learning English. CAI is now used as a supplement to traditional teacher-directed instruction. However, there exist many problems in the process of applying multimedia to the teaching field. These problems are worthy of serious consideration and must be urgently resolved. This paper discusses how to use multimedia to create a scientific English teaching model of Human-Computer Interaction (HCI) to improve the quality of teaching and learning.
\end{abstract}

Keywords-Multimedia; Human-Computer Interaction; English teaching; educational reform; personalized learning

\section{INTRODUCTION}

To be attuned to the 21st century and the global trends of educational reform, English teachers in colleges and universities must engage in educational reform in order to promote student achievement and preparation for global competitiveness and cooperation. The rapid development of science and technology provides us a unique opportunity to vigorously promote the reform and development of English teaching. Digital multimedia tools offer a key to educational reform [1]. Multimedia can create the favorable conditions that help students become better and more autonomous learners. At the same time, multimedia can build a personalized learning environment for students. In the teaching process, English teachers can use multimedia to create a three-dimensional open-learning environment. Students can quickly improve their integrated English skills in oral, listening, reading and writing by Human-computer interaction (HCI) and develop autonomy.

\section{DEFINITION OF HUMAN-COMPUTER INTERACTION}

The term "Human-Computer Interaction" (HCI) was adopted in the mid-1980s. HCI is also called "Man-Machine Interaction" or "Man-Machine Interfacing". It can be defined in many possible ways. The Curriculum Development Group of the ACM Special Interest Group on Human-Computer Interaction(SIGCHI) stated (Hewett et al, 1992, p.5): "Human-computer interaction is discipline concerned with the design, evaluation \& implementation of interactive computer systems for human use and with the study of major phenomena surrounding them." Dix et al. (1993, p.13) offered the following definition: "HCI is, put simply, the study of people, computer technology and the ways these influence each other. We study HCI to determine how we can make this computer technology more usable by people.” Carroll (2002) suggested, "HCI is the study and practice of usability. It is about understanding and creating software and other technology that people will want to use, will be able to use, and will find effective when used." The following is another definition for HCI proposed by Brad Myers in his article: "HCI is the study of how people design, implement, and use interactive computer systems, and how computers affect individuals, organizations, and society. This encompasses not only ease of use but also new interaction techniques for supporting user tasks, providing better access to information, and creating more powerful forms of communication [2].

\section{STATUS AND CHALLENGES OF ENGLISH CURRICULUM}

At present, as mankind marches into the new millennium, economic globalization and informationization in social life are developing rapidly, making English become more and more important. Learning English not only meets the needs of the Information Age, but also conduces to the overall development of students and the improvement in quality of talent. In addition, learning English sharpens their cognitive abilities and learn new concepts. At the same time, learning English can foster students' cooperative spirit, their spirit of innovation and character development. English has become the most widely used language in the various aspects of human life as one of the most important information carriers. Many countries, including China, regard English education as an important part of civic education in the Basic Education Development Strategy, and have placed it in a prominent position. Therefore, the active promotion of English education has become a necessity.

Since the reform and opening up in China, there has been a massive drive to scale up English education. And remarkable achievements have been made in English teaching. However, English language education at present is still unable to meet the needs of China's economic and social development. English language curricular reform is the inevitable way to solve this problem. Curricular reform of English teaching includes two important parts, namely, comprehensive optimization and reorganization of teaching content and comprehensive reform of teaching methods that provides a foundation for the optimization and 
reorganization of teaching contents. Moreover, the reform of teaching method assures the implementation of the teaching content after optimization and reorganization.

\section{Benefits of Multimedia Computer Assisted INSTRUCTION}

Along with advancing computing technology, especially with the rapid development of computer network and multimedia technology, reforms in teaching methods are being carried out in the teaching community. Multimedia courseware and network multimedia CAI courseware have proliferated, demonstrating the strong momentum of the development of a new round of reform of teaching methods. It can be said with certainty that using multimedia and network technology to reform teaching methods is in the ascendant.

Multimedia technology shapes a new direction of reforms in English teaching methods as well. In just a few years, with the using of various necessary college English courseware and the investment in computer multimedia hardware, all kinds of multimedia teaching forms have been adopted [3]. The application of multimedia technology has completely changed the traditional teaching and learning mode. The traditional mode of learning is biased toward a teachercentric mode. However, multimedia equipment contributed to student-centered learning. Student-centered instruction is focused on the needs, abilities and learning styles of individual students. It is personalized, engaging, and vigorous, giving students more space for learning and thinking. Multimedia tools create an authentic language teaching and learning environment in which students can easily see the learning materials of different styles and forms. The vivid pictures, melodious music and pure American or British accent can grab students' attention very easily. It is reasonable to hope that students who do not love learning English will naturally show interest in English. A famous saying, from Albert Einstein, is that interest is the best teacher.

Multimedia English teaching is conducive to self-directed learning and can promote students' personalized learning. Each student can operate the computer according to his or her own preferences and the level of knowledge of foreign languages, choose the corresponding teaching program independently to learn, and fully realize the human-computer interaction, with a special emphasis on the student-contents interaction, which is self-learning with materials.

\section{Problems of Multimedia-Assisted English TEACHING}

It is true that the application of multimedia technology in the field of English teaching resolves the contradiction between the teaching content and the teaching time that previously existed in the traditional teaching for a long time. But some problems also arise with it.

\section{A. Less Interaction Between Teachers and Students}

One critical problem in China is that English teachers are in short supply in universities and colleges. According to statistics given by the Division for Teaching English as a
Second Language of Beihang University, the teacher-student ratio is $1: 130$ [4]. On the other hand, teaching equipment is deficient. For the above reasons, Chinese English teachers generally teach English in large classes. Overcrowded classrooms have more negative than positive effects.

There are usually too many students for the educator to cater to directly and many do not receive the education they deserve because of this [5]. One of the features of multimedia-assisted English teaching is that teachers present a large amount of information to students in class. But because class time is limited [6], sufficient teacher-student interaction as prescribed by the teaching plan is very hard to achieve. Most students have limited chances to participate in lessons. As time passes, students' enthusiasm for learning English withers.

\section{B. Over-relying on Multimedia Courseware}

Some teachers over-rely on multimedia courseware. They only focus on the computer, but ignore the natural language environment and feedback between the teacher and students. Rowntree (1977) said feedback is the lifeblood of learning. But its importance is not reflected in the English teaching. The goal of most teachers is just to accomplish the teaching task.

In order to able to reach it, they quickly present the new information and knowledge in the multimedia courseware to students in rapid succession. This teaching method is similar with the "duck-feeding education style." We call it "wearing new shoes to walk the old road" [7], because the function multimedia performed here is just like an electronic blackboard and multimedia becomes a substitute for chalkboards and textbooks.

\section{Low efficiency of multimedia in teaching English due to multimedia abuse}

Multimedia courseware has high capacity, so it can present large amounts of information in a short time to students. When information is presented via computer-based multimedia in class, it's very difficult for students to keep up with these presentations. They also can not fully digest what they have learned in the class. In computer-assisted teaching, massive amounts of information are presented to students instantly. In the face of so much new knowledge, students are eager to learn and try their best to absorb all the information.

At the same time, they wish to have a chance to practice in order to know how to apply that knowledge in real life after they graduate. However, teachers cannot give them enough time to do so because the teaching hours are limited. As a result, what the students have to do is only to receive the information passively. They have no time to understand, digest, absorb and apply what they have seen and heard in class. Because teachers are busy in presenting multimedia courseware they have less time to talk with their students, and so most students have no chance to speak English in class. Basically there is less feedback between teachers and students. Teachers don't know what teaching effectiveness is like. 
The main purpose that students learn a second language is to communicate with foreigners in real-life contexts. If they don't practice their English speaking, they cannot improve their speaking skills at all. Without a doubt, multimedia is a good helper for teachers to promote the teaching quality. But how to effectively use multimedia resources in teaching is a question that is worth considering.

VI. USING MULTIMEDIA TO CREATE A SCIENTIFIC

ENGLISH TEACHING MODEL OF HUMAN-COMPUTER INTERACTION TO IMPROVE THE QUALITY OF TEACHING AND LEARNING

Human Computer Interaction is characterized by the GUI design and multimodal $\mathrm{I} / \mathrm{O}$ devices. By interfacing appliances with the computer or embedding the computer within the appliance, humans can not only interact with the computer but also with sophisticated devices through the computer [8]. Through networking, humans can acquire information and interact with the external world through the computer.

In the learning process, students can ask questions, answer questions and receive timely feedback and guidance from their teachers. Feedback is critical to improving performance. Providing feedback can reinforce what has been learned and can also correct any misconceptions [9]. Multimedia provides a complex multi-sensory experience in exploring our world through the presentation of information through text, graphics, images, audio and video [10]. The colorful human-machine interface is conducive to stimulating students' interest in learning, improving students' understanding of knowledge and strengthening memory.

The rich web content provides favorable conditions for students to carry on the personalized learning. There is no limit on time and space for students to use the network resources. Students can learn at their own pace. Moreover, they can make a determination on the progress of study corresponding to their own characteristics, levels, needs and goals, and they can independently choose the suitable materials and content for learning.

Furthermore, students can remain aware of their academic strengths and weaknesses using self-tests. Accordingly, they can regulate their own learning process and create new learning goals. In such a language-learning environment, students need to learn to be independent. They have to learn to self-manage and self-regulate and they must learn to use the network resources on their own as well, choosing and organizing the language materials by themselves.

In the learning process of self-discovery and self-inquiry, students can increase their metacognitive skills and gradually discover and use effective learning strategies in their learning.

The following are some suggestions to create a scientific English teaching model of human-computer interaction.

\section{A. Secure basic conditions}

Colleges and universities should increase investment in building more computer-assisted language learning labs that provide the most basic condition for human-computer interaction teaching and learning. On the other hand, colleges and universities should introduce some good English teaching software, for example, the Live ABC English Learning System to teachers. In addition, colleges and universities should build a robust campus network infrastructure. The high-performance network can provide best-in-class network access to users. All these can make human-computer interaction teaching easier to carry out smoothly.

\section{B. Establish a self-learning center}

Lifelong learning and self-learning has gradually become a general trend of education development. Universities and colleges should establish a self-learning center to help students learn how to go about becoming better and more independent language learners [11] and how to develop the student skills required to manage their own learning. At the same time, the self-learning center should teach students how to use computer aided learning packages, DVDs, the Internet etc. and offer learning materials and help students to learn better.

\section{Change teaching concepts}

In the process of multimedia English teaching, the English teacher is not only the person who communicates information, but also someone who processes information. In this regard, the role of English teachers has completely changed. A teacher is no longer merely the person who imparts knowledge. Teachers have become learning organizers and coordinators.

Concurrently, teachers must improve the professional expertise. Not only do they have to master multimedia basic skills, but also they should master the skills required to design effective interactive multimedia courseware and produce practical interactive multimedia courseware. To accomplish this, they must keep learning. Teachers should get some training to equip themselves with the proper skills for interactive multimedia creation in order to be able to effectively use multimedia tools for their electronic content.

\section{Handle the relationship among multimedia, ,teachers and students correctly}

The most common function of multimedia is to assist or support the teacher. Multimedia can provide a large amount of instructional information to the students for the purpose of English learning and accelerate the process of information searching. But this is not to say that multimedia instruction is a substitute for teachers. Teachers are always the facilitators of whole classes, whether in the multimedia classroom or in the traditional classroom [12]. Teachers are directors rather than merely transmitters of knowledge in the teaching and learning process. Students are actors and active agents instead of passive receivers of information. Give students the chance to participate more in class. Multimedia can only be used to create preconditions for learning to take place and enhance learning materials, making learning interesting and active, so multimedia resources are just useful tools to help students collect and organize content, to create and present 
ideas, to foster collaboration and construct knowledge actively.

\section{E. Lay emphasis on emotional interactions between teachers and students}

The face-to-face communication between teachers and students is an effective way of teaching and learning English. Multimedia cannot replace the interpersonal communication between students and teachers in classroom teaching.

Teachers should use a variety of learning activities, making the classroom a positive and effective learning environment [13] such as making an English speech, discussing some issues and role-playing. Students need opportunities to talk about what they are learning, relate it to past experiences and apply it to their daily lives. They must make sense of what they learn for themselves. [14] Meanwhile teachers can give them immediate feedback and encouragement that can make students become more confident.

\section{CONCLUSION}

The English teaching model of human-computer interaction realized student-centered, teacher-led instruction and created a foreign-language environment in the classroom with computers. Human-computer interaction teaching increases student contact time with English and provides more opportunities for students to use English, mobilizing students' learning enthusiasm [15]. If English teachers use human-computer interaction reasonably and effectively, the quality of college English teaching must be improved greatly.

\section{REFERENCES}

[1] Don Hardaway MIS, and Richard P. Will, "Digital multimedia offers key to educational reform," Communications of the ACM, Volume 40 Issue 4, April 1997 , Pages 90-96.

[2] Brad Myers, Jim Hollan and Isabel Cruz, "Strategic Directions in Human Computer Interaction,” ACM Computing Surveys 28(4), December 1996.

[3] Li Lu, "Research on English Teaching in Interactive Network," IPCSIT vol. 25 (2012) (C) (2012) IACSIT Press, Singapore.

[4] http://fld.buaa.edu.cn/English/View.aspx?id=1466.

[5] http://www.helium.com/items/2057283-effects-of-overcrowdedclassrooms.

[6] http://www.circleartstheatre.org/wordpress/?page_id=203.

[7] Tanja Sargent, Mingyu Chen, Yi-Jung Wu and Chentong Chen, "Wearing New Shoes to Walk the Old Road: The Negotiation of Opposing Imperatives in High School New Curriculum Classes in China,” Emerald Group Publishing Limited, 2011, pp.79-98.

[8] http://www.niitcrcs.com/content/research/hci.htm.

[9] J. P. Gee, "Learning by design: Good video games as learning machines,” E-Learning, (2), 5-16, 2005.

[10] R. E. Mayer, "Multimedia learning," New York: Cambridge University Press, 2001.

[11] http://www.langcent.manchester.ac.uk/resources/online/supportadvice/learning-guide/.

[12] Abbas Pourhosein Gilakjani, "The Significant Role of Multimedia in Motivating EFL Learners' Interest in English Language Learning,” I.J.Modern Education and Computer Science, April 2012, p. 57-66.

[13] http://para.unl.edu/legacy/Organization/lesson1.php.

[14] http://www.langcent.manchester.ac.uk/resources/online/supportadvice/learning-guide/.

[15] Qin Huihua , "Mobilizing Students' Learning Enthusiasm to Improve the Efficiency of Chinese Classroom Teaching,’Journal of Guilin Normal College, February 2011. 